\title{
CRISP (crayfish and rice integrated system of production): 1. Modelling rice (Oryza sativa) growth and production
}

\author{
P.M. Anastácio ${ }^{a, *}$, A.F. Frias ${ }^{b}$, J.C. Marques ${ }^{b}$ \\ a IMAR-Department of Ecology, University of Évora, Apartado 94, 7001 Évora codex, Portugal \\ b IMAR-Department of Zoology, University of Coimbra, 3000 Coimbra, Portugal
}

Received 15 December 1997; accepted 15 March 1999

\begin{abstract}
A ecological sub-model for rice growth, adapted to the culture processes used in the lower Mondego river valley (Portugal), is presented. The structure of the model is based on the production of carbohydrates by the photosynthesis. Parallel structures were used to simulate the development stage of the crop, and the tillering process. The model is composed of 11 state variables, 14 forcing functions, 22 rate processes, 9 parameters and 17 switches, regulatory processes and calculated values. Simulations were performed for periods ranging from January 1995 to October 1996. During this period the simulation results were compared with data on aerial rice biomass and also on the tiller density. In addition, the simulated final rice production parameters were compared with the observed values for both years. It can be stated that the model performs well in what regards prediction of final production parameters but it underestimated rice biomass during the growth period. Although at this stage the model is mainly directed towards research, the final purpose is the management of crayfish and rice production. In order to achieve this aim, it will be necessary to couple several sub-models. (c) 1999 Elsevier Science B.V. All rights reserved.
\end{abstract}

Keywords: Rice; Oryza sativa; Model; Integrated production; Crayfish; Procambarus clarkii

\section{Introduction}

Double cropping of crayfish and rice is practised in Louisiana for several decades (Chien and Avault, 1979; Chien et al., 1980; Johnson et al.,

\footnotetext{
* Corresponding author. Tel.: + 351-66-745385; fax: + 35166-709498.

E-mail address: anast@evunix.uevora.pt (P.M. Anastácio)
}

1980, 1982; Brunson and Griffin, 1988). Nevertheless, in Louisiana the environmental conditions and the techniques used to grow rice are different from the ones in the Iberian Peninsula. A tool was needed to plan and to analyse solutions involving double cropping of crayfish and rice. In fact, an improved planning and optimisation of efforts involved in rice or rice-crayfish farming can be achieved by means of ecological models (Anastácio et al., 1995). 
Previous papers have addressed the problem (Anastácio et al., 1993, 1995), but their purpose was mostly to simulate scenarios in order to prepare strategies for research. From the ecological point of view, it is important to understand the dynamics of the system. In fact, at this point the rice model can change from descriptive to explanatory (Penning de Vries et al., 1989). In other words, the mechanisms and processes that cause the behaviour of the system are now quantitatively described. Moreover, new data is now available on the rice growth dynamics, providing a chance for a better calibration.

Modelling of rice crop growth has been a widely explored topic, and several papers have been presented (e.g. Herrera-Reyes, 1991; Penning de Vries et al., 1991; Gao et al., 1992; Bouman, 1993; Kropff et al., 1994a,b; Pinnschmidt et al., 1995; Huang et al., 1996; Wopereis et al., 1996). In fact, rice (Oryza sativa) is a preferential target for modelling due to its importance as food to at least $40 \%$ of the world population (Bellido, 1991). The aim of this paper is to present a ecological sub-model for rice growth, adapted to the locally used culture processes, and suitable for linking with other models.

\section{Study site}

The lower Mondego river valley is located in the central region of Portugal $\left(40^{\circ} 10^{\prime} \mathrm{N}, 8^{\circ} 41^{\prime}\right.$ $\mathrm{W})$. Average temperature of the air is $15.5^{\circ} \mathrm{C}$ (average of 30 years) and yearly precipitation ranges from 800 to $1190 \mathrm{~mm}$ (Ferreira, 1991). The valley consists of $\approx 15000$ ha and the main agricultural production is rice, which in 1983 occupied about $60 \%$ of the valley (Ferreira, 1991). The above mentioned crayfish, $P$. clarkii has been detected in this region since 1984, and is considered by farmers as the cause of substantial damage to the local rice production.

\section{Background data}

Data was obtained in the 'Seminário' farm, near the Pranto river, during the years of 1995 and 1996 (Anastácio and Marques, 1996; Anastácio et al., 1999, Frias et al. in prep.). The dynamics of two 0.7 ha rice fields were monitored on a fortnight basis, providing data for the calibration of ecological models (Frias et al. in prep.). The purpose was not only to obtain data on rice growth but also to follow the ecological succession observed throughout the year. The water level and the variety of data to obtain, was the determining factor for the sampling method. Therefore an Hesse stream bottom sampler (Klam et al., 1990) with a frame area of $254.5 \mathrm{~cm}^{2}$ and $0.5 \mathrm{~mm}$ mesh size, was used. Aquatic fauna and flora could be caught simultaneously, whenever there was water in the field. Five replicates were obtained in each field at each sampling occasion. Data collected included: rice plants (aerial parts and roots), weeds, algae, and macroinvertebrates. Rice plant dry weight biomasses (DW) were determined after dried for $48 \mathrm{~h}$ at $60^{\circ} \mathrm{C}$. Before the harvest, five randomly chosen areas of $1 \mathrm{~m}^{2}$ were also sampled in each field (Anastácio et al., 1999). The purpose was to obtain data on final rice production parameters using standard methods (Gomez, 1972) thus avoiding the predictable large errors due to the small sampling areas.

Several enclosure experiments were performed in parallel with the monitorization program (Anastácio and Marques, 1996; Anastácio et al., 1999). Such enclosures were used to assess the impact on rice by several crayfish densities. In the 1996 experiments there was a total destruction $(100 \%)$ of rice in the enclosures with densities of 3 and 5 crayfish $\mathrm{m}^{-2}$. At lower densities ( 1 crayfish $\mathrm{m}^{-2}$ ) the average decrease in grain production attributable to crayfish was $41.61 \%$. Previous experiments indicated that the damages to the rice crop were caused mainly at the beginning of the growing season.

Meteorological data were obtained daily from a nearby station of the Portuguese Meteorological Institute. For this model only the air temperature and cloud cover were used. 


\section{Conceptual model and parallel structures}

Model assumptions are that water and nutrient availability are not limiting, that macrophytes are not significant competitors and that plagues other than crayfish infestation are not significant. This type of rice crop may be situated in production level 1 because its growth rate depends basically on the weather and the present state of the crop (Penning de Vries et al., 1989). In fact, a lot of fertilisers (Santos, 1990), and herbicides (Silva, 1972) are currently used.

The structure of the main part of the model describing the production of carbohydrates by the photosynthesis, is shown in Fig. 1. A part of these carbohydrates leave the carbohydrate pool due to maintenance respiration. All the rest is directed to the roots and shoots and finally to the different plant organs. In Fig. 2 the fate of the carbohydrates produced by photosynthesis is summarised. The proportion of the carbohydrates being used in the construction of each plant organ (partition coefficient) depends largely on the developmental stage (Penning de Vries et al., 1989; Kropff et al., 1994a). In the model, after the assimilates have reached a plant organ, its biomass may be lost by senescence (of leaves), crayfish destruction (of shoots), natural mortality, or simply by the harvest. Remobilization can also contribute to a increase in the biomass of the panicle and grain.

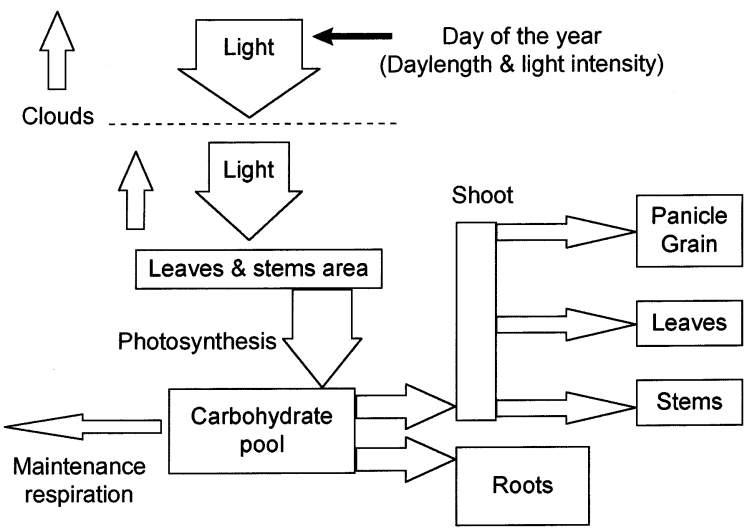

Fig. 1. Conceptual diagram of the rice model showing a structure based on light interception, photosynthesis and carbohydrate movement to the plant organs.

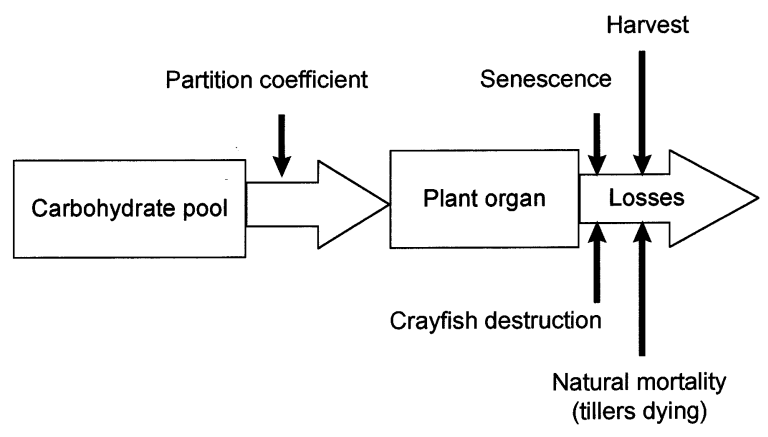

Fig. 2. Diagram of the model processes directing gains and losses in the weight of each plant organ.

A parallel structure was used to simulate the developmental stage of the crop (Fig. 3). It has values ranging from 0 to 2 , i.e. from sowing to harvest. The development rate is dependent on the air temperature, the carbohydrates produced, and the developmental stage. If the temperature drops below a threshold level the crop is killed and the developmental stage will be set to zero. This solution is similar to the one used by Gao et al. (1992) but different in the equations used.

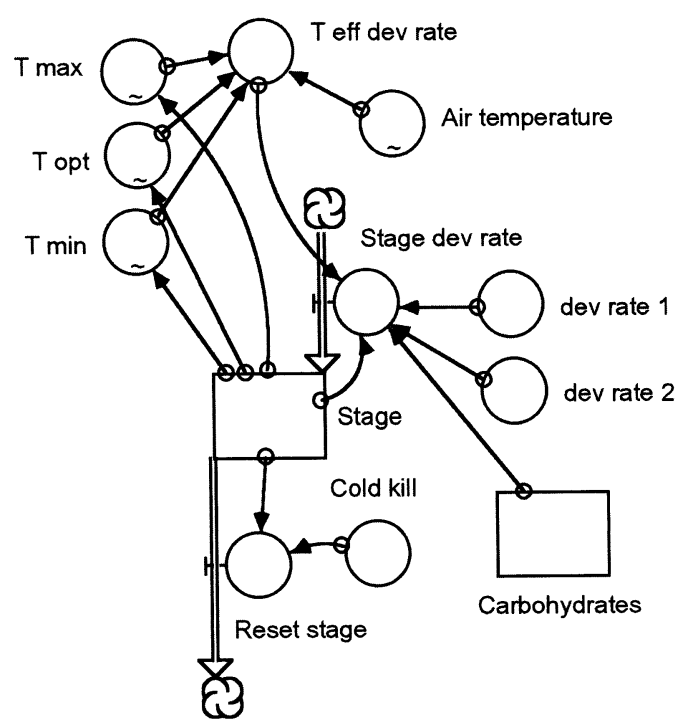

Fig. 3. Stella diagram of the processes involved in the progression of the crop developmental stage. ' $T_{\min }$ ', ' $T_{\max }$ ' and ' $T_{\text {opt }}$ ' are respectively the minimum, maximum and optimum temperatures for development. ' $T$ eff dev rate' is the temperature effect on the development rate. 'Cold kill' is the effect of very low temperatures. 'dev rate' is used as an abbreviation of 'development rate'. 
The measured daily cloud cover (in a scale from 1 to 8 ), the photoperiod and the day of the year will influence the light reaching the crop. In addition, the amount of light captured by the crop, will depend on the surface of leaves and stems present.

Another parallel structure was used in order to simulate tiller development and mortality. It performs an important role in the simulation of crayfish damages.

\section{Equations}

A forcing function, described as a Stella ${ }^{\circledR}$ II graph (version 3.0.7), was used to simulate the clear sky solar radiation for a latitude of $40^{\circ}$, according to data from Hamon et al. (in Bowie et al., 1985). Only $50 \%$ of the radiation from the light spectrum is photosynthetically active (Penning de Vries et al., 1989), moreover, clouds are responsible for a decrease in the radiation reaching the crop. Therefore, the following equation was used to calculate the amount of photosynthetically active radiation (PAR) reaching the crop. It is basically a formula for light attenuation by clouds adapted from Rich (1973):

$\mathrm{PAR}=0.5 \cdot \operatorname{sun} \cdot\left(1-0.65 \cdot \frac{\text { cloud cover }}{8}\right)$

where 'sun' is the clear sky solar radiation, and 'cloud cover' is the fraction of the sky covered by clouds, measured in a scale 1-8.

Because of reflectivity and transmitivity, only $80 \%$ of the incoming light is absorbed by the canopy (Penning de Vries et al., 1989). In this case we used the equation (obeying Bouguer-Lambert law) for the short wave solar radiation penetrating canopy from Monsi and Saeki (Etherington, 1982). Instead of using the approach developed by Goudriaan (1986) for the calculation of photosynthesis, a simplification was used. The integral of Monsi and Saeki equation was determined for a leaf area index (LAI) from zero to the crop LAI and divided by the LAI to give the average light reaching leaves in the canopy. LAI was substituted by 'Total surface'. absorbed radiation

$$
=0.8 \frac{\frac{\text { PAR }}{0.6}-\frac{\text { PAR }}{\exp (0.6 \cdot \text { Total surface }) 0.6}}{\text { Total surface }}
$$

'Total surface' is the total photosynthetically active plant surface in ha leaf/ha. In this case it is calculated as leaf surface plus $50 \%$ of the stem surface because the photosynthetic capacity of stems is 50\% lower (Kropff et al., 1994a).

The following equation for photosynthesis calculates production of carbohydrates as $\mathrm{Kg} / \mathrm{ha} /$ day. It corresponds to the $\mathrm{CO}_{2}$ assimilation-light response of individual leaves (Goudriaan, 1982 in Kropff et al., 1994a) multiplied by the 'Total surface', the ratio $\mathrm{CH}_{2} \mathrm{O} / \mathrm{CO}_{2}(30 / 44)$, and the 'Daylength' expressed in hours of sunlight:

Photosynthesis

$=$ Daylength $\cdot \frac{30}{44} \cdot$ Total surf $\cdot \max$ rate phot

$\cdot\left[1-\exp \left(-\right.\right.$ int eff use $\left.\left.\cdot \frac{\text { absorbed rad }}{\max \text { rate phot }}\right)\right]$

In this equation, 'init eff use' is the initial light use efficiency expressed as $\left(\mathrm{Kg} \mathrm{CO}_{2} /\right.$ ha leaf $\left./ \mathrm{hr}\right) /(\mathrm{J} /$ $\mathrm{m}^{2}$ leaf $\left./ \mathrm{s}\right)$. It was calculated from the equation $0.6-0.006^{*} \mathrm{Air}$ temperature $\left({ }^{\circ} \mathrm{C}\right)$. The relation with temperature is linear, with a value of 0.54 at $10^{\circ} \mathrm{C}$ and 0.36 at $40^{\circ} \mathrm{C}$ (Ehleringer and Pearcy in Kropff et al., 1994b). 'max rate phot' is the maximum rate of photosynthesis, i.e. the gross assimilation rate at light saturation, expressed as $\mathrm{Kg}$ $\mathrm{CO}_{2} /$ ha leaf $/ \mathrm{h}$. This rate is influenced by temperature, $\mathrm{N}$ content, age of the leaves and the environmental conditions that the leaf was exposed to (Kropff et al., 1994b). For simplicity we considered that at the end of the crop development the max rate of photosynthesis is $50 \%$ lower. Temperature dependency was similar to the one used for the development rate.

To calculate the stem and leaf surfaces the specific stem and leaf weights are needed. They are expressed in ha/ $\mathrm{Kg}$ of stems or leaves and considered to vary depending on the developmental stage: 
IF stage $<1$ THEN Specific stem weight $=$ $0.0005-0.00025$ stage

ELSE Specific stem weight $=0.00025$

IF stage $<0.3$ THEN Specific leaf weight $=$ $0.008-0.0215$ stage

ELSE specific leaf weight $=0.0015$

IF, THEN and ELSE act as logical statements. The equations were estimated by calibration of the slopes, intercepts and ending points.

The portion of the carbohydrates consumed in maintenance respiration is dependent on the air temperature and can be calculated similarly to the model ORYZA1 (Kropff et al., 1994a) by the equation:

maintenace respiration $=0.02 \times 2\left(\frac{T-25}{10}\right) \times$ leaves

$$
\begin{aligned}
& +0.003 \times 2\left(\frac{T-25}{10}\right) \\
& \times \text { panicles } \& \text { grain } \\
& +0.01 \times 2\left(\frac{T-25}{10}\right) \\
& \times(\text { roots }+ \text { stems })
\end{aligned}
$$

'leaves', 'panicles \& grain', 'roots' and 'stems' are expressed as the respective dry weights in $\mathrm{Kg} / \mathrm{ha}$. ' $T$ ' is the air temperature in ${ }^{\circ} \mathrm{C}$.

The development rate was considered dependent on the air temperature and also on the development stage (Fig. 3). This is similar to Gao et al. (1992), but different equations were used. After flowering (stage equal to 1) development proceeds at a faster rate, resulting in practice in two different speeds of development. Temperature dependency acts as a regulating factor for the rate of development. The formula chosen was from Lehman et al. cited by Bowie et al. (1985), and is divided in two:

$\exp \left[-2.3\left(\frac{\left(\text { Air temp }-T_{\text {opt }}\right)}{T_{\text {min }}-T_{\text {opt }}}\right)^{2}\right]$

when the air temperature is smaller or equal to the optimum temperature. Or: $\exp \left[-2.3\left(\frac{\left(\text { Air temp }-T_{\text {opt }}\right)}{T_{\text {max }}-T_{\text {opt }}}\right)^{2}\right]$

when the air temperature is higher than the optimum temperature. 'Air temp' is the air temperature, ' $T_{\min }$ ', ' $T_{\max }$ ' and ' $T_{\mathrm{opt}}$ ' are respectively the minimum, maximum and optimum temperatures for development. It is important to notice that the minimum, maximum and optimum temperatures are variable depending on the stage of development of the crop (de Data in Bellido, 1991). They were simulated using a Stella graphical function.

The formation of new tillers was considered dependent on the quantity of carbohydrates entering the shoot and on the total number of shoots present:

Tillering $=\frac{\frac{\text { flux shoot }}{\text { tiller factor }}-(\text { Tillers }+ \text { Main shoots })}{15}$

The equation is similar to the one of Penning de Vries et al. (1989). 'flux shoot' is the quantity of carbohydrates entering the shoot, 'tiller factor' is the amount of carbohydrates needed to initiate and maintain a tiller, 'Tillers' is the number of tillers per ha and 'Main_shoots' is the number of stems (per ha) formed directly from the germination of the seeds. It was considered that tillering would occur during stages 0 to 1.5 , and only when the number of tillers plus main shoots was below 6000000 (per ha).

The regulation of the maximum grain production ( $\mathrm{m}_{-}$prod) was achieved with the aid of the equations:

$\mathrm{m} \_$prod $=1.108 \cdot$ growth_PI_Flowering

flux_pan_grain $=$ part_pan

$$
\text { _grain_shoot }\left(1 \text { - panicle_grain } / m_{-} \text {prod }\right)
$$

In which 'growth_PI_Flowering' is the observed plant growth from panicle initiation to flowering; 'flux_pan_grain' is the increase in weight of the panicle and grain; 'part_pan_grain' is the proportion of the organic material entering the shoot that will be directed to the panicle and grain; and 'panicle_grain' is the weight of the 
panicle and grain. The first of the two equations is an adaptation of the method used by Kropff et al. (1994a). Approximately $26 \%$ of the growth of panicle and grain biomass is due to remobilization from other plant organs (Yoshida, 1981 in Bellido, 1991). In this case it was simulated daily as a portion of the stem and leaf material.

Only a portion of the seeds will germinate, a few days after sowing, and the seeds will die if they do not germinate or if they are destroyed by crayfish. Crayfish destruction is the destruction rate (proportion/day) of seeds and shoots when the development stage is below 0.3 . It was simulated using the equation:

Crayfish destruction $=$ Crayfish

$$
\text { - biomass } \times 0.0011
$$

where 'crayfish_biomass' is expressed as $\mathrm{Kg}$ of crayfish live weight per ha.

Table 1 presents a list of the model components, useful for quick reference.

\section{Parameters}

If some of the parameter values are unknown, estimation can be made automatically by appropriate software (e.g. PSI, Jørgensen, 1994) or by implementing numerical optimisation procedures by means of programming (e.g. flexible polyhedron search, Marsili-Libelli, 1992; Nielsen, 1995). Due to the nature of the Stella ${ }^{\circledR}$ software, automatic calibration was not performed. Instead, we performed trial and error calibrations.

The model was calibrated for situations with and without crayfish infestation and the parameter values are presented in Tables 2 and 3. A crayfish biomass of $125 \mathrm{Kg} / \mathrm{ha}$ corresponds to a infestation of 1 adult $/ \mathrm{m}^{2}$ and this value was used to verify the model performance in a situation with crayfish infestation. The values of ' $\mathrm{dev}$ rate 1', 'dev rate 2', 'tiller factor', 'max phot', and 'remob \%' were found by calibration around the usual literature ranges. 'sowing day' and 'germ prop' correspond to actual field values. Any other values without biological meaning were directly included in the equations.

\section{Simulation results and validation status}

Simulations were performed for periods ranging from January 1995 to October 1996. During this period the simulation results of a situation without crayfish infestation were compared with the field data on aerial rice biomass (Fig. 4), and tiller density (Fig. 5). In addition, the simulated final rice production parameters were compared with the observed values for both years obtained by standard field procedures (Table 4).

The model performed nicely in the prediction of the final production values. The best match was obtained for the final tiller number in 1995, with a underestimation of only $0.09 \%$. The worse match was obtained for the final shoot biomass (DW) in 1996, with an underestimation of $5.01 \%$. In the course of the temporal simulation, both aerial biomass and tiller density were underestimated when compared with data obtained from the small area sampling devices. The difference between the observed and simulated values is higher when the biomass reaches the maximum values. This corresponds also to the period of maximum tiller density.

\section{Sensitivity analysis}

According to Jørgensen (1994) the purpose of a sensitivity analysis is to provide a measure of the sensitivity of parameters, forcing functions or submodels to the most important state variables in a model. This will provide an additional knowledge of the properties of the model.

It is frequent that sensitivity analysis is conducted independently for each parameter but this procedure can be misleading (Elston, 1992). For the simplicity of the final form of the paper, no results of a combined sensitivity analysis of several parameters are presented. Nevertheless such analysis was performed (manually) in the early stages of the model construction in order to obtain a correct calibration.

Sensitivity analysis were performed with \pm 10 and $\pm 50 \%$ variations in the parameter values (Tables 2 and 3) with and without crayfish presence (125 kg live weight /ha). Independently of 
Table 1

Components of the model and units used

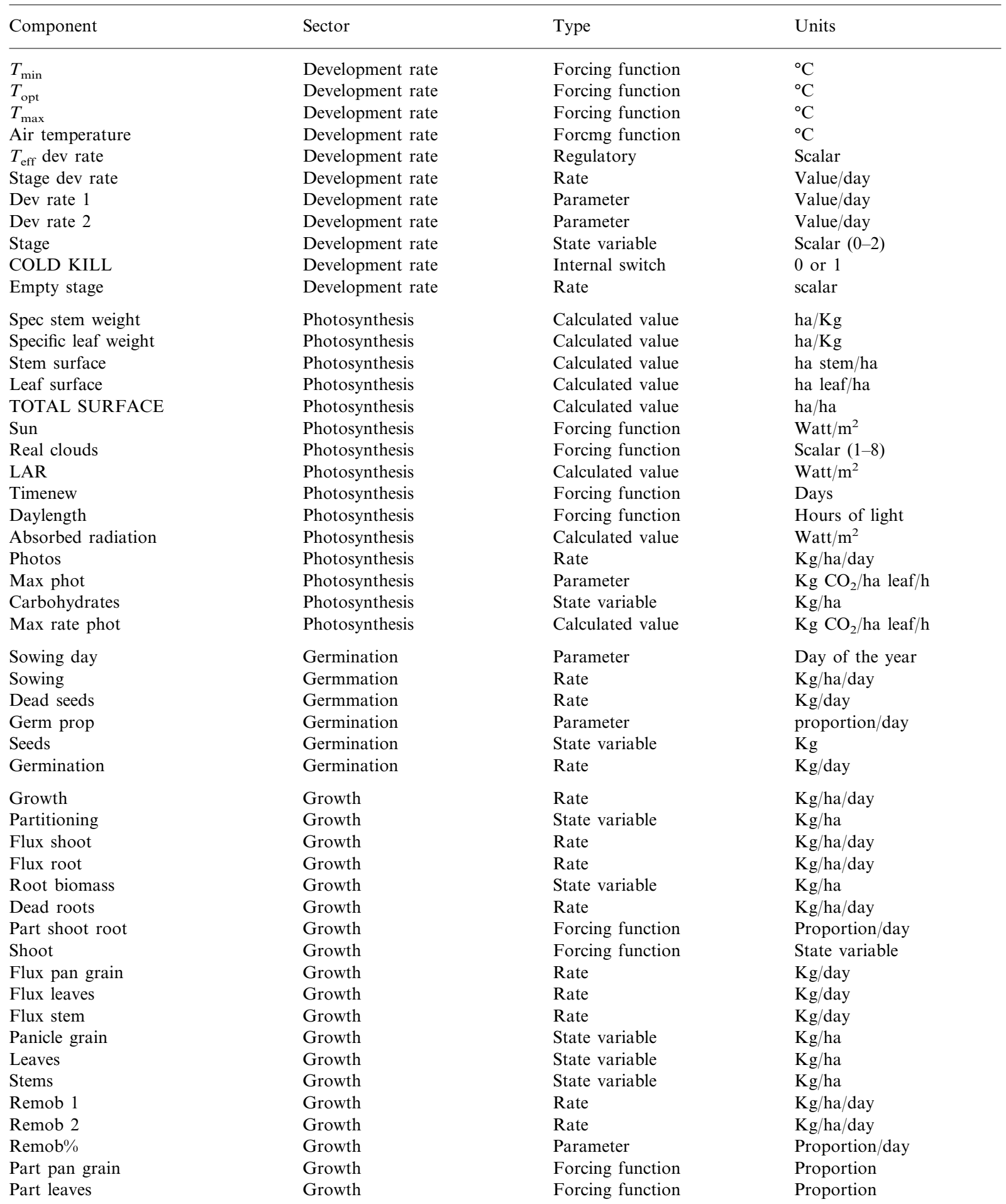


Table 1 (Continued)

\begin{tabular}{|c|c|c|c|}
\hline Component & Sector & Type & Units \\
\hline Part stem & Growth & Forcing function & Proportion \\
\hline Senescence & Growth & Forcing function & Proportion \\
\hline Shoot biomass & Growth & Calculated value & $\mathrm{Kg} / \mathrm{ha}$ \\
\hline Rice biomass & Growth & Calculated value & $\mathrm{Kg} / \mathrm{ha}$ \\
\hline Straw & Growth & Rate & $\mathrm{Kg} / \mathrm{ha} /$ day \\
\hline Empty GPIF & Growth & Rate & $\mathrm{Kg} /$ day \\
\hline $\mathrm{m}$ prod & Growth & Calculated value & $\mathrm{Kg} / \mathrm{ha}$ \\
\hline Tiller factor & Tiller number & Parameter & $\mathrm{Kg}$ \\
\hline Tillering & Tiller number & Rate & New tillers/ha/day \\
\hline Tillers & Tiller number & State variable & Tillers/ha \\
\hline Main shoots & Tiller number & State variable & Number/ha \\
\hline Shots dead & Tiller number & Rate & Number/ha/day \\
\hline Rice mortality & Tiller number & Calculated value & Number/ha/day \\
\hline Total shoots & Tiller number & Calculated value & Number/ha \\
\hline Crayfish destruction & Crayfish effects & Calculated value & Proportion/day \\
\hline Crayfish biomass & Crayfish effects & Parameter & $\mathrm{Kg} / \mathrm{ha}$ \\
\hline
\end{tabular}

the situation under study, panicle-and-grain and aerial biomasses were not very sensitive to changes in the daily percentage of remobilization (remob\%). It can be stated that the model is extremely sensitive to changes in 'dev rate 1'. This stands true for the simulated values of both the panicle and grain biomass and aerial biomass with or without crayfish. Other less sensitive parameters are 'max phot', 'dev rate 2', and the 'sowing day'.

\section{Discussion and future developments}

At this stage the model is directed mainly towards research and according to Jørgensen (1994) we can classify it as a dynamic, non-linear, reductionistic and deterministic compartment model. It can also be classified as explanatory in the sense of Penning de Vries et al. (1989), because it includes a qualitative description of the mechanisms and processes that drive the behaviour of the system. The model is composed of 11 state variables, 14 forcing functions, 22 rate processes, 9 parameters and 17 switches, regulatory processes and calculated values. One cannot consider it a summary model but attempts were made to avoid excessive complexity. Several processes were ignored, such as: (1) the $\mathrm{CO}_{2}$ depletion inside the canopy; (2) the daily oscillation (morning to afternoon) in the light intensity, which was substituted by an average value for daylight hours; (3) the effect of several leaf layers receiving different light intensities which was replaced by a calculation of the average light reaching the leaves. Some of these processes are of minor importance, but for example the simplification of the effect of the leaf layers (point 3) will cause an overestimation of the photosynthesis especially at high light intensities.

In general simulated values were lower than the ones obtained in the field. Nevertheless one must remember that during the growing period sampling areas were lower than the usually recommended areas, which may lead to distortions in the results. The emphasis put on a good match with the final production values is explained by the higher degree of reliability of these values. Several attempts were 
Table 2

Sensitivity of panicle and grain biomass to \pm 10 and $\pm 50 \%$ oscillations in the parameter values

\begin{tabular}{|c|c|c|c|c|}
\hline \multirow[t]{2}{*}{ Parameter name (and value) } & \multirow[t]{2}{*}{ Units } & \multirow[t]{2}{*}{ Value tested } & \multicolumn{2}{|l|}{ Sensitivity } \\
\hline & & & With crayfish & Without crayfish \\
\hline Crayfish biomass (125) & $\mathrm{Kg} / \mathrm{ha}$ & $\begin{array}{l}188 \\
138 \\
113 \\
62.5\end{array}$ & $\begin{array}{l}-1.180 \\
-1.242 \\
1.165 \\
0.876\end{array}$ & \\
\hline Dev rate $1(0.023)$ & Value/day & $\begin{array}{l}0.0345 \\
0.0253 \\
0.0207 \\
0.0115\end{array}$ & $\begin{array}{l}-1.721 \\
-4.034 \\
3.764 \\
-1.896\end{array}$ & $\begin{array}{l}-1.087 \\
-0.646 \\
2.469 \\
1.450\end{array}$ \\
\hline Dev rate $2(0.035)$ & Value/day & $\begin{array}{l}0.0525 \\
0.0385 \\
0.0315 \\
0.0175\end{array}$ & $\begin{array}{l}-1.083 \\
-1.721 \\
1.212 \\
0.808\end{array}$ & $\begin{array}{l}-1.314 \\
-3.822 \\
3.199 \\
2.247\end{array}$ \\
\hline Tiller factor $(0.00007)$ & $\mathrm{Kg}$ & $\begin{array}{l}0.000105 \\
0.000077 \\
0.000063 \\
0.000035\end{array}$ & $\begin{array}{l}0.133 \\
0.174 \\
-0.201 \\
-0.296\end{array}$ & $\begin{array}{l}0.453 \\
0.697 \\
-1.369 \\
-0.429\end{array}$ \\
\hline Germ prop $(0.45)$ & Proportion & $\begin{array}{l}0.675 \\
0.495 \\
0.405 \\
0.225\end{array}$ & $\begin{array}{l}0.468 \\
0.639 \\
-0.760 \\
-1.162\end{array}$ & $\begin{array}{l}0.370 \\
0.554 \\
-1.177 \\
-0.025\end{array}$ \\
\hline
\end{tabular}

made in order to match the observed and simulated values without increasing the complexity and the number of equations involved. Actually, that was accomplished at the cost of the reliability in the prediction of the biomass lost during the growth process. For a better match between the values, biomass losses reached magnitudes over the biomass at harvest. Although no field measurements were performed on this matter, we believe that it would be unrealistic. Finally, it should be noticed that a comparison of the evolu- tion of a real rice crop and the simulated values is seldom seem in the literature.

Coupling with other sub-models will predictably be accomplished through LAI, straw decomposition, crop height, crayfish destruction and nitrogen absorption. LAI will influence the amount of solar energy reaching the water. This will affect both the temperature of the water and the photosynthetic rate of algae. Straw decomposition will affect the nitrogen cycling processes, moreover it will provide shelter and food for a 
rich macroinvertebrate community. The height of the crop, together with the LAI will interfere with the role of the wind in the re-oxygenation process. At this level, crayfish biomass was used as a parameter with a constant value. After coupling with the crayfish sub-model the crayfish biomass will be a state variable. Finally, nitrogen is used by the rice plants, with variable needs depending on the crop developmental stage and biomass.

Some of the previously built rice models are more complete. Nevertheless, their purpose is basically to simulate rice production while our purpose is to provide a model that can easily be coupled with several others without a serious increase in complexity. In fact, a comparison of this model with the one of Kropff et al. (1994a) shows a greater simplicity in our model. This had to be done if a higher level of integration between several components of the ecosystem was to be obtained in the future. Simplicity increases the

Table 3

Sensitivity of rice aerial biomass to \pm 10 and $\pm 50 \%$ oscillations in the parameter values

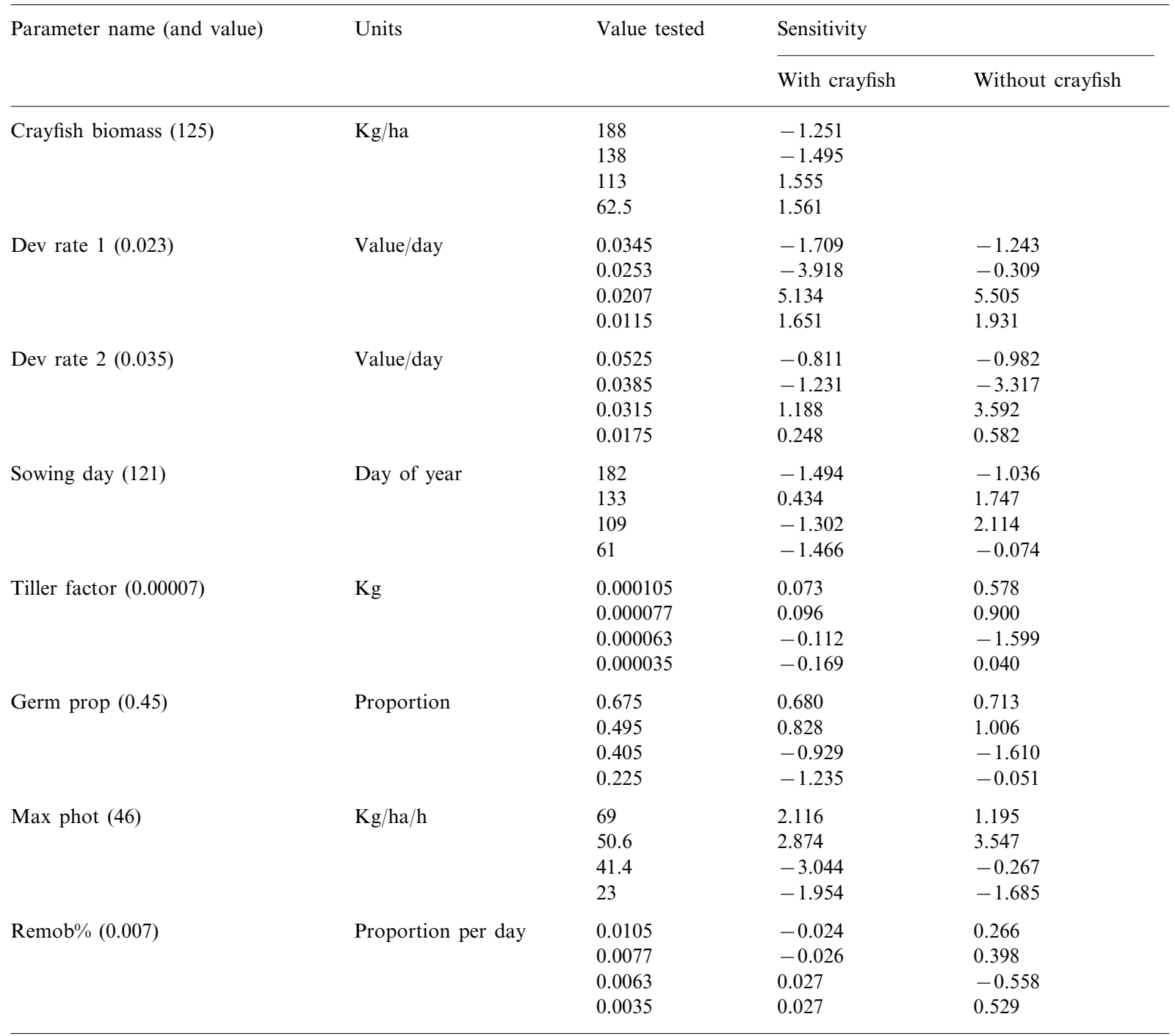




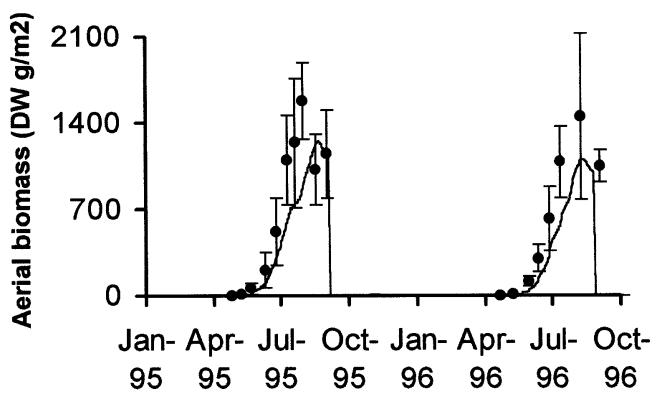

Fig. 4. Simulated versus observed values of the rice aerial biomass (with no crayfish present), expressed in dry weight (DW). Dark line represents simulated values, and observed values are presented with standard deviations.

possibility of articulation with other models simulating other biological entities of the ecosystem In the simplification process, some of the authenticity of the simulated processes is lost. This means that simplicity may sacrifice accuracy, but it may also be a solution for a more generalised application of the model.

\section{Acknowledgements}

This work was sponsored by the EU in the scope of the R\&D project AIR 3-CT-94-2432 and also by JNICT and the PRAXIS XXI Program (Portugal). The authors are indebted to Mr. António Carriço who provided the rice fields.

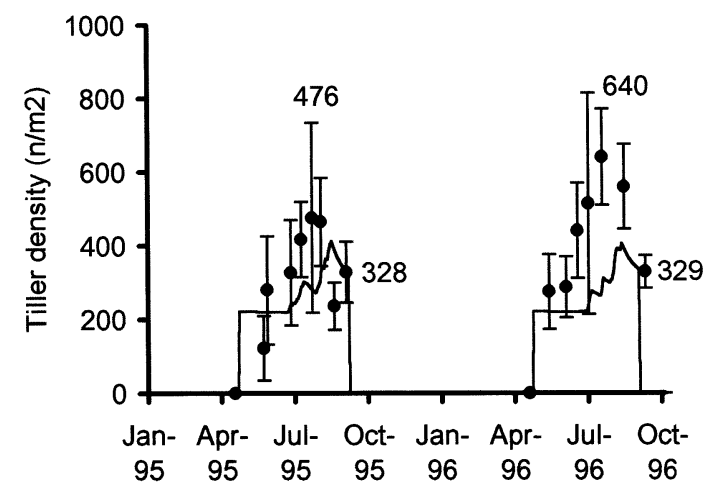

Fig. 5. Simulated versus observed values of the rice tiller density (with no crayfish present), expressed as number per $\mathrm{m}^{2}$. Dark line represents simulated values and observed values are presented with standard deviations. Maximum and final observed values are also presented.
Table 4

Estimated versus observed final production $\left(\mathrm{g} / \mathrm{m}^{2}\right)$ for rice (Oryza saliva)

\begin{tabular}{llll}
\hline Parameter & Year & Estimated & Observed \\
\hline Final shoot biomass & 1995 & 1128.17 & 1148.80 \\
$\left(\mathrm{DW}{ }^{\mathrm{a}} \mathrm{g} / \mathrm{m}^{2}\right)$ & 1996 & 992.77 & 1045.15 \\
Final grain biomass $\left.^{\mathrm{a}} \mathrm{g} / \mathrm{m}^{2}\right)$ & 1995 & 659.89 & 682.35 \\
$(\mathrm{DW}$ & 1996 & 583.90 & 585.71 \\
Final tiller number & 1995 & 327.53 & 327.81 \\
$\left(\right.$ number $\left./ \mathrm{m}^{2}\right)$ & 1996 & 336.47 & 328.80
\end{tabular}

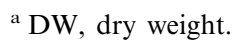

\section{References}

Anastácio, P.M., Frias, A.F., Marques, J.C., 1999, Impact of crayfish densities on wet seeded rice and the inefficiency of a non-ionic surfactant as an Ecotechnological solution. Ecol. Eng. In press

Anastácio, P.M., Marques, J.C., 1996. Crayfish (Procambarus clarkii) effects on initial stages of rice growth in the Lower Mondego river valley, Portugal. Freshwater Crayfish 11, 608-617.

Anastácio, P.M., Nielsen S.N., Marques, J.C., Jørgensen, S.E. 1993. Rice and crayfish production in the lower Mondego river valley: a management model for farmers. Proc. Int. Congress on Modelling and Simulation, Perth, pp. 16871692.

Anastácio, P.M., Nielsen, S.N., Marques, J.C., Jørgensen, S.E., 1995. Integrated production of crayfish and rice: a management model. Ecol. Eng. 4, 199-210.

Bellido, L.L., 1991. Cereales. Mundi-Prensa, Madrid, pp. 420-491.

Bouman, B.A.M. 1993. ORYZA_W: Rice growth model for irrigated and water limited conditions. Wageningen, DLO, WAO, IRRI. p. 1-159.

Bowie, G.L., Mills, W.B., Porcella, D.B., Campbell, C.L., Pagenkopf, J.R., Rupp, G.L., Johnson, K.M., Chan, P.W.H., Gherini, S.A., Chamberlain, C.E., 1985. Rates, Constants and Kinetics formulations in surface water modelling. United States Environmental Protection Agency-Environmental Research Laboratory - EPA/600/3-85/040, Athens, USA, p. 455.

Brunson, N.W., Griffin, J.I., 1988. Comparison of rice-crayfish and grain sorghum-crayfish double cropping systems. Aquaculture 72, 265-272.

Chien, Y.H., Avault, J.W., 1979. Double cropping rice, Oryza sativa and red swamp crawfish, Procambarus clarkii. Freshwater Crayfish 4, 263-272.

Chien, Y.H., Avault Jr, J.W., 1980. Production of crayfish in rice fields. The Progressive Fish Culturist 42, 67-71.

Elston, D.A., 1992. Sensitivity analysis in the presence of correlated parameter estimates. Ecol. Model. 64, 11-22.

Etherington, J.R., 1982. Plants in ecosystems. In: Etherington, J.R. (Ed.), Environment and plant ecology. Wiley, London, pp. 377-416. 
Ferreira, F.S., 1991. O baixo mondego sem projecto e com projecto. Semente 3, 26-34.

Gao, L., Jin, Z., Huang, Y., Zhang, L., 1992. Rice clock model - a computer model to simulate rice development. Agric. For. Meteor. 60, 1-16.

Gomez, K.A., 1972. Techniques for field experiments with rice. The International Rice Research Institute, Los Banos, Laguna, Phillipines, p. 46.

Goudriaan, 1986. A simple and fast numerical method for the computation of daily totals of crop photosynthesis. Agric. For. Meteor. 38, 249-254.

Herrera-Reyes, C.G., 1991. History of modelling at IRRI. IRRI Research Paper Series 151, 5-10.

Huang, Y., Gao, L., Jin, Z., Chen, H., 1996. A software package for optimizing rice production management based on growth simulation and feedback control. Agric. Syst. 50, 335-354.

Johnson, W.B., Avault Jr, J.W., 1980. Some effects of poultry manure supplementation to rice-crawfish (Oryza sativaProcambarus spp.) experimental earthen impoundments. Abstracts Aquaculture, New Orleans, p. 3.

Johnson, W.B.J.R., Avault Jr, J.W., 1982. Effects of poultry waste supplementatition to rice-crayfish (Oryza sativaProcambarus clarkii) culture ponds. Aquaculture 29, 109123.

Jørgensen, S.E., 1994. Fundamentals of ecological modelling, 2nd edition. Elsevier, Amsterdam, p. 1-628.

Klam, J.D., Lewis, P.A., Fulk, F., Lazorchak, J.M., 1990. Macroinvertebrate field and laboratory methods for evaluating the biological integrity of surface waters. EPA-600/490-030. US Environmental Protection Agency, Cincinnati, Ohio, p. 256.

Kropff, M.J., Laar H.H.v., Matthews, R.B. Goudriaan, J. and Berge, H.F.M.t. 1994a. Description of the model ORYZA1 (Version 1.3). In: Oryza 1. An ecophysiological model for irrigated rice production, M.J. Kropff, H.H.v. Laar, R.B. Matthews (Eds.), SARP Research Proceedings, Wageningen. pp. 5-41.

Kropff, M.J., Laar, H.H.v. Matthews, R.B. Torres, R.O. Peng S., Cassman K.G. 1994b. Model parameterization. In: Oryza 1. An ecophysiological model for irrigated rice production, M.J. Kropff, H.H.v. Laar, R.B. Matthews (Eds.), SARP Research Proceedings, Wageningen. pp. 4355.

Marsili-Libelli, S., 1992. Parameter estimation of ecological models., Ecol. Model., 62, pp. 233-258.

Nielsen, S.N., 1995. Optimization of energy in a structural dynamic model. Ecol. Model. 77, 111-122.

Penning de Vries, F.W.T.P., Jansen, D.M., Berge, H.F.M.t., Bakema, A., 1989. Simulation of ecophysiological processes of growth in several annual crops. Simulation Monographs 29. Pudoc, Wageningen, p. 271.

Penning de Vries, F.W.T.P., Kropff, M.J., Teng, P.S., Kirk, G.J.D., 1991. Systems simulation at IRRI. IRRI Research Paper Series 151, 3-4.

Pinnschmidt, H., Batchelor, W.D., Teng, P.S., 1995. Simulation of multiple species pest damage in rice using the CERES-rice. Agric. Syst. 48, 193-222.

Rich, L.G., 1973. Environmental systems engineering. McGraw-Hill, NY.

Santos, J.Q. 1990. A fertilizaçao da cultura do arroz. Technical report. Direcção Regional da Agricultura do Ribatejo e Oeste. p. 22.

Silva, M.V., 1972. A culture do arroz. Livraria Clássica Editora A.M.Teixeira \& Ca. (Filhos), Lda, Lisbon, p. 171.

Wopereis, M.C.S., Bouman, B.A.M., Tuong, T.P., Berge, H.F.M.t., Kropff, M.J. 1996. ORYZA_W: Rice growth model for irrigated and rainfed environments. DLO, WAO, IRRI, NARSA. p. 159. 